\title{
Socioeconomic position as a risk factor for BPA exposure in a sample of Egyptian children
}

\author{
Azza A. Gabr ${ }^{1}$, Nermine N. Mahfouz ${ }^{1 *}$, Mones M. Abu Shady ${ }^{1}$, Mai M. Youssef ${ }^{1}$, Ebtissam M. Salah El-Din ${ }^{1}$, \\ Alyaa H Kamhawy ${ }^{1}$, Jihan Hussein ${ }^{2}$, Tarek S. Ibrahim ${ }^{1}$, M. A. Abbas ${ }^{1}$ \\ ${ }^{1}$ Child Health Department, Medical Division, National Research Centre (NRC), (33 ${ }^{\text {rd }}$ El Bohouth st, former El Tahrir st, Dokki, Cairo, Egypt. \\ ${ }^{2}$ Medical Biochemistry Department, Medical Division, National Research Centre (NRC), (33 ${ }^{\text {rd }}$ El Bohouth st, former El Tahrir st, Dokki, Cairo, Egypt.
}

\section{ARTICLE INFO \\ Article history: \\ Received on: 11/09/2017 \\ Accepted on: 07/11/2017 \\ Available online: 30/12/2017}

\section{Key words:}

Bisphenol A, children, socioeconomic level, exposure sources.

\begin{abstract}
Background: Bisphenol $\mathrm{A}$ is an endocrine-disrupting chemical that interferes with hormone action and contributes to disease and disability. Objective: To estimate the concentrations of urinary Bisphenol A in a sample of Egyptian children from different socioeconomic levels Methods: A cross-sectional study included 167 children aged 2-18 years of both sexes. Socio-demographic data were evaluated and estimation of urinary Bisphenol A using high performance liquid chromatography was done. Urinary Bisphenol A, was categorized into quartiles $(<1.3,1.3-<2.6,2.6-4.9,>4.9) \mathrm{ng} / \mathrm{mL}$ and was associated and analyzed with the social class. Results: The total urinary Bisphenol A ranged from 0.1 to $18.9 \mathrm{ng} / \mathrm{ml}$ with a mean $1.29( \pm 2.09)$, median 0.67 and geometric mean 0.68 . According to parental occupation and education children were divided into 3 social classes: low (21.5\%), middle (41.1\%), and high (37.3\%). Children of high class have Bisphenol A levels significantly higher than middle and low classes, $p=0.01$. Conclusion: Urinary Bisphenol A concentrations exhibited low values in more than three fourths of the studied group indicating low exposure. The highest levels were detected in children from high socioeconomic standard. Excessive use of plastic bottles, microwave plastic wares and consumption of canned food may be the sources of exposure.
\end{abstract}

\section{INTRODUCTION}

Bisphenol A (BPA) is a widely used chemical in the manufacture of polycarbonate plastics and epoxy resins. There are universal and widespread products using BPA that include: reusable plastic food and beverage containers, baby bottles, tableware, microwave oven ware, some food packaging materials

\footnotetext{
* Corresponding Author

Nermine N. Mahfouz, Department of Child Health, in National Research Centre (33 ${ }^{\text {rd }}$ El Bohouth st, former El Tahrir st, Dokki, Cairo, Egypt. Address: 16th Darih Saad Street, Kasr El Eini, Cairo, Egypt. Tel: + 20 01223585320,E-mail: nerminabil @yahoo.com
}

and linings for cans used for food (Inadera, 2015). Those have been used in consumer products for over 40 years (FDA, 2010). There is an increasing incidence of exposure to BSA worldwide, with an average increase of $2.5-3 \%$ per year (Vandenberg et al., 2007) Reports on the Egyptian food market indicated an increased demand for packaged and convenience foods and the canned food industry appeared to grow rapidly with the reduction of fresh produce (Abdel-Aziz, 2008). According to the National Food Consumption Survey, an increasing number of Egyptian households reported consumption of ready-made foods and carbonated soft drinks (Galal, 2002). A closer look at changing food patterns and the consumer market may provide a better understanding of BPA exposure in vulnerable populations in our country. 
Animal studies have suggested that BPA exposure may have a role in the development of weight gain, insulin resistance, pancreatic endocrine dysfunction, thyroid hormone disruption, and diabetes (Rubin and Soto, 2009; Newbold et al., 2009; Shankar and Teppala, 2011). Scientists are hardly working to examine the relationship between the health effects seen in animals exposed to BPA and similar effects that are on the rise in human populations (Trasande et al., 2016).

Identifying populations that are highly exposed to environmental chemicals is important for protecting public health and preventing health inequalities. Identifying differential patterns of exposure in populations can also provide useful information for hypotheses about possible sources of exposure that, especially for many emerging chemicals of concern, are poorly understood. This study investigates differences by measures of socioeconomic position (SEP) in body burden of BPA in a sample of Egyptian children and adolescents.

\section{SUBJECTS AND METHODS}

The study is a cross sectional one that included 167 apparently healthy children who were randomly selected from nurseries, primary, and preparatory schools in Giza, 95 (56.9\%) males and $72(43.1 \%$ ) females, age ranged between 2.12 and 18.8 years. Each child and/or a parent enrolled in the study was subjected to Structured Questionnaire to collect data about Socio demographic factors that was assessed by parental education and employment.

Sources of BPA exposure assessment tool was a specific food frequency questionnaire which included the monthly ingestion of canned food and beverage e.g. fruits, vegetables, soft drinks and fast food Spot urine samples were collected for determination of levels of BPA using high performance liquid chromatography (HPLC) (Matsumoto et al., 2003).

\section{Ethical considerations}

Permission to perform the study was granted by the Ministry of Education and the directors of the schools that participated in the research from 2012-2014. Written consents was obtained from the parents and another one from each student to be involved in the research. The levels of urinary creatinine was determined by Henry and Gutman \& Bergmeyer respectively (Henry, 1974; Gutman and Bergmeyer, 1974). BPA concentration was adjusted to the urinary creatinine concentration to correct for the urine dilution (Barr et al., 2005)

\section{Social status assessment}

Assessment of social status of the family was done according to Park and Park, 1979. Two markers of social status (educational attainment and occupation) of both father and mother were assessed. Educational attainment was assessed on a 7-point scale (1 for illiterate, 2 for Primary, 4 for Preparatory, 5 for Secondary and 7 for University graduated). Current occupational status was assessed on a 7-point scale (1 for housewife or unskilled worker, 2 for Industrial worker, agricultural and in general services, 4 for skilled worker, 5 for semiprofessional and 7 for professional).

The two indices were added to yield a single indicator of social status. Scoring criteria are: Low social class: $\leq 8$, Middle social class: 9-18 and High social class: 19-28. Thus families were divided into three groups: low, middle or high social status (Park and Park, 1979).

\section{Methods for statistical analysis}

Data analysis was performed using SPSS version 21 (SSPS Inc, Pennsylvania, USA). Continuous data were expressed as mean $\pm \mathrm{SD}$, while Categorical data were expressed as frequencies and percentages. Urinary BPA and BPA/Creatinine levels were log-transformed to improve normality of the distribution. The main exposure of interest, urinary BPA, was categorized into quartiles and were associated and analyzed with the social class groups using the two-tailed chi-square test. ANOVA and post-Hoc tests were done to compare urinary BPA concentration in different social class groups. P-value was considered significant at $\mathrm{p}<0.05$.

\section{RESULTS}

The study included 167 children 95 (56.9\%) males and $72(43.1 \%)$ females, age ranged between 2.12 and 18.8 years. Children were divided into 3 social classes according to Park and Park, low (21.5\%) middle $(41.1 \%)$ and high $(37.3 \%)$ table 1. Children of high social class were using bottled water more than those of low social class, Pearson (Chi-Square $=7.389$, $\mathrm{p}=0.007$ ). ( $\mathrm{P}$-value was considered significant at $\mathrm{p}<0.05$ ).

Table 1: Social class distribution.

\begin{tabular}{llll}
\hline & Social class & Frequency & Percent \\
\hline \multirow{4}{*}{ Valid } & Low social class & 34 & 21.5 \\
\cline { 2 - 4 } & Middle social class & 65 & 41.1 \\
\cline { 2 - 4 } & High social class & 59 & 37.3 \\
\cline { 2 - 4 } & Total & 158 & 100.0 \\
\hline Missing & System & 9 & \\
\hline Total & & 167 & \\
\hline
\end{tabular}

No statistical differences between the three social classes were found as regards reusing of empty water bottles, using of plastic containers for water storage or usage soft drink cans but using microwave utensils showed a significant difference being higher in the high social class (pearson Chi-Square $=6.273 \mathrm{p}=$ 0.012) (P-value was considered significant at $\mathrm{p}<0.05$ ) (table 2 ).

The total urinary BPA was ranging from (0.1 to 18.9 $\mathrm{ng} / \mathrm{ml}$ ) with a mean value of 1.29, Standard Deviation 2.09, median 0.67 and geometric mean (GM) of 0.68. ANOVA and post-Hoc tests were done to compare urinary BPA concentration in different social class groups. Urinary BPA and BPA /Creatinine levels were log-transformed to improve normality of the distribution. Log total BPA, BPA/Creatinine gm and log BPA /creatinine gm showed significant statistical differences between the three groups being highest in the high social class group (table 4). 
Table 2: Some practices in relation to BPA in different social classes.

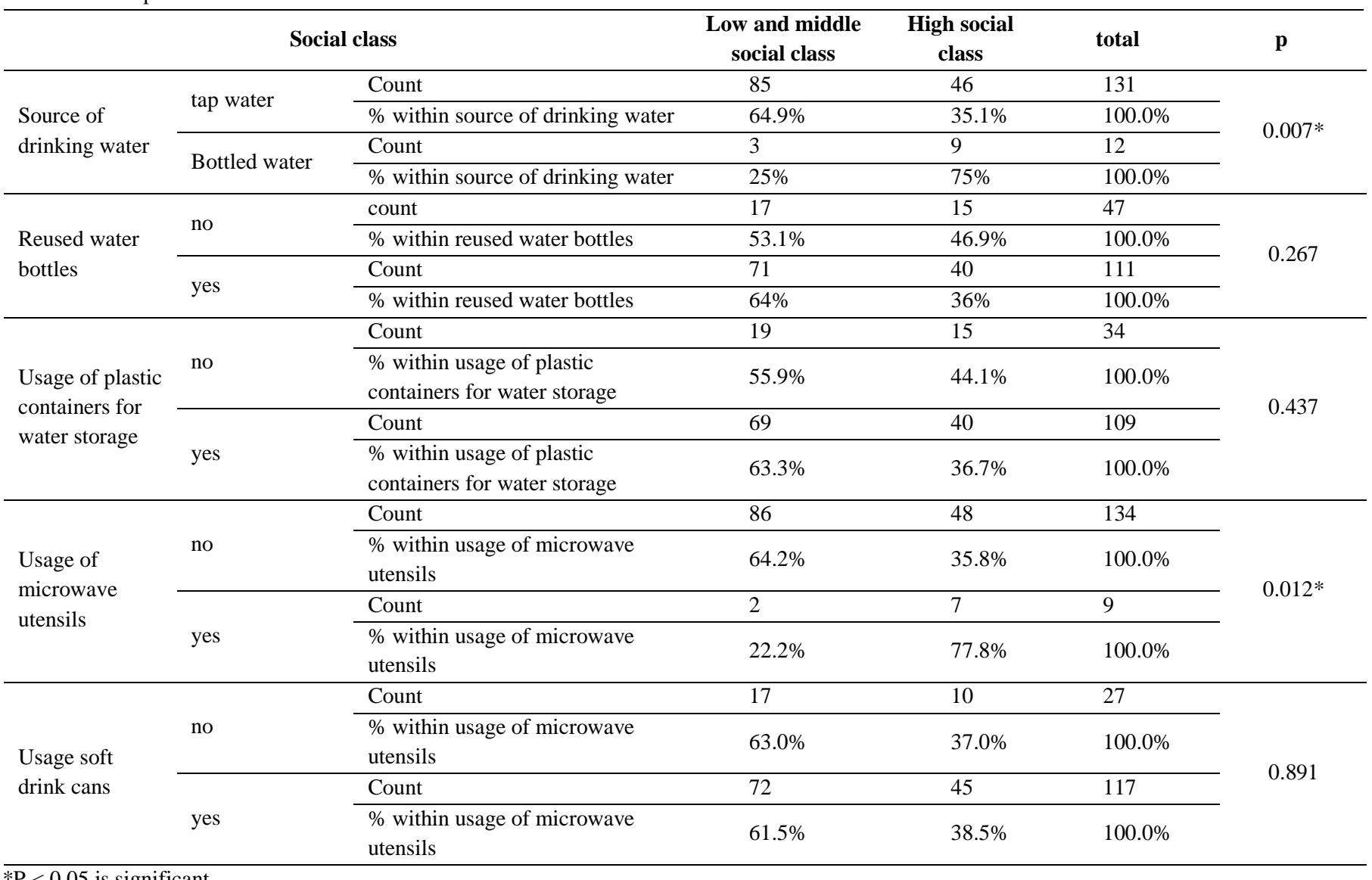

$* \mathrm{P}<0.05$ is significant.

Table 3: BPA quartile distribution.

\begin{tabular}{ccc}
\hline BPA quartile & Frequency & Valid Percent \\
\hline BPA $<1.3$ & 129 & 77.2 \\
BPA 1.3 $-<2.6$ & 19 & 11.4 \\
BPA 2.6 -4.9 & 14 & 8.4 \\
BPA $>4.9$ & 5 & 3.0 \\
Total & 167 & 100.0 \\
\hline
\end{tabular}

Table 4: ANOVA comparing BPA levels between social classes.

\begin{tabular}{|c|c|c|c|c|c|c|}
\hline & & $\mathbf{N}$ & Mean & Std. Deviation & $\mathbf{F}$ & Sig. \\
\hline \multirow[b]{2}{*}{ Total BPA } & Low social class & 34 & 1.30 & 2.08 & \multirow[b]{2}{*}{0.98} & \multirow[b]{2}{*}{0.378} \\
\hline & Middle social class & 65 & 1.00 & 1.54 & & \\
\hline \multirow{3}{*}{ Log total BPA } & Low social class & 34 & -0.17 & 0.47 & \multirow{3}{*}{3.671} & \multirow{3}{*}{$0.028 *$} \\
\hline & Middle social class & 65 & -0.28 & 0.47 & & \\
\hline & High social class & 59 & -5.71 & 0.43 & & \\
\hline \multirow[t]{2}{*}{$\mathrm{BPA} /$ creatinine gm } & Middle social class & 60 & 566.95 & 927.50 & \multirow[t]{2}{*}{3.575} & \multirow[t]{2}{*}{$0.031 *$} \\
\hline & High social class & 53 & 1369.55 & 2425.67 & & \\
\hline \multirow{3}{*}{$\begin{array}{l}\text { log BPA /creatinine } \\
\text { gm }\end{array}$} & Low social class & 32 & 2.62 & 0.46 & \multirow{3}{*}{6.686} & \multirow{3}{*}{$0.002 *$} \\
\hline & Middle social class & 60 & 2.46 & 0.50 & & \\
\hline & High social class & 53 & 2.80 & 0.53 & & \\
\hline
\end{tabular}


Chi square test shows that high social class children have BPA levels significantly higher than middle and low social class children, $\mathrm{p}=0.014$, $(\mathrm{P}$-value was considered significant at $\mathrm{p}<0.05)$ (table 5).

Table 5: Cross tabulation of BPA quartiles and social classes.

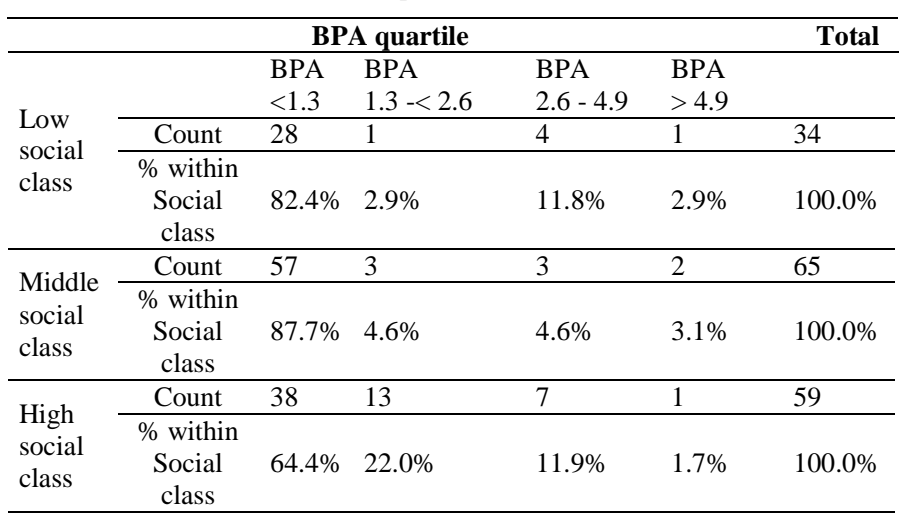

Pearson chi square $=15.9, \mathrm{p}=0.014$ ( $\mathrm{P}$-value was considered significant at $\mathrm{p}<0.05)$.

\section{DISCUSSION}

The ongoing growth and maturation of children body systems make them more vulnerable to the harmful effects of all environmental hazards. In addition their longer life expectancy in comparison to adults, results in a greater chance for them to get chronic illnesses, thus special attention is paid to children as regards exposure to environmental pollutants (Scheuplein et al., 2002; WHO 2004, 2011). Therefore we focused on this age group in our cross sectional study.

One hundred sixty seven children participated in the study. Ninety five males $(56.9 \%)$ and seventy two females (43.1\%), their age ranged between 2.12 and 18.8 years. This wide age range is beneficial to estimate the pattern of exposure to BPA and to figure out its peak of hazards. This is matching with the study done in Australia on children from 0-15 years old, where each five year increment in age was reflected on BPA measurements by a constant decrement factor of 0.4 (AL Heffernan et al., 2014).

Personal interviews were conducted by a well-trained interviewer for collection of socioeconomic data to investigate the association between urinary BPA concentrations in a sample of Egyptian children and their different social levels.

Information were obtained through the implementation of a well-established battery of Arabic questionnaires hybrid to similar studies and finely adjusted to our society. Two indices of social status were put into consideration, the parental educational attainment and the parental occupation According to the parents 'answers, the children were divided into 3 social classes, in the light of the textbook of Park and Park. A .Low social class, a middle class and a high class that constituted $21.5 \%, 41.1 \%$ and $37.3 \%$ respectively as illustrated in table1. A comparable stratification was done by Nelson et al, who used four indices, two of which were similar to ours. The classification of the socioeconomic positions was done according to family income, educational level, occupation and food security. In contrast in a pilot Egyptian study, conducted by Nahar et al, the social stratification was done only according to residency whether in urban or rural region. Same classification of urban and rural population was chosen by Covaci et al. in a study on BPA exposure in six European countries. Although the social grouping parameters differ from one study to another, still a common concept of agreement exists on the great influential effect of social position on practices and trends that may determine the degree of exposure to BPA.

As regards the potential environmental pathways of exposure to BPA, most concern was about the oral route. The exposure assessment tool was a specific food frequency questionnaire which included the monthly ingestion of canned food and beverage e.g. fruits, vegetables, soft drinks and fast food. This was matching the study done by Koch and Calafat, who concluded that ingestion is the major route of BPA exposure. Also Vandenberg et al described the "per mouth" as the highest pathway of exposure (Koch and Calafat, 2009; Vandenberg et al. 2007). In addition, Von Goetz et al, ranked cans packaging among the top ways of foodstuff contamination with BSA (Von Goetz et al. 2010)

Also certain hazardous habits were assessed to find out their impact on BPA levels. This was done through inquiries about certain trends and behaviors. These included the storage of food and water in plastic boxes or jars, the usage of plastic microwave utensils, the reuse of plastic water bottles and water drinking from tanks. The same malpractices involving the usagelreuse of plastic containers were the focus of attention of Nahar et al in a study on Egyptian girls. They found that it presented a real reflection of BPA exposure level (Nahar et al, 2012).

An influence of socioeconomic level was detected on certain lifestyle aspects. Children of high social class were using bottled water more than those of low social class, Pearson ChiSquare $=13.054, \mathrm{p}=0.000$. Microwave utensils also showed a significant difference being in higher use within the high social class (pearson Chi-Square $=6.065 \mathrm{p}=0.014$ ). But no statistical differences between the three social classes were found as regards reusing of empty water bottles or using of plastic containers for water storage, table 2 .

Urine samples were collected for determination of levels of BPA and the levels of urinary Creatinine. The total urinary BPA was ranging from $(0.1$ to $18.9 \mathrm{ng} / \mathrm{ml})$ with a mean value of 1.29 , Standard Deviation 2.09, median 0.67 and geometric mean (GM) of 0.68. In a similar Egyptian study done by Nahar et al, on girls from 10-13 years old, the GM was 0.84 which is very close to GM value in our study group (Nahar et al, 2012). Also a review was done on previous worldwide studies that have examined the total urinary BPA concentrations in young children. In Germany a survey was done on children from 3 to 14 years old, they found the least GM 2.22 in the age range of 3 to 5 years old (Becker et al. 2009). Still their least GM value was higher than our GM in the whole study group. In an Australian study, done on children from 
0-15 years old the urinary total BSA range was 1.08 to $4.14 \mathrm{ng} / \mathrm{ml}$ which was quite similar to the one we detected in our study of $<1.3$ to $4.9 \mathrm{ng} \backslash \mathrm{ml}$. But their GM of $2.57 \mathrm{ng} / \mathrm{ml}$ was more than the triple of our GM value (AL Heffernan et al, 2014). In the Canadian Survey involving children from 6 to 19 years old, the minimal GM of 1.3 was double our GM. It was detected in those having 6-12 years old (Bushnik et al. 2010). In a large European study involving children of 5-12 years old recruited from six European countries, the GM of urinary BPA was $1.97 \mu \mathrm{g} / \mathrm{L}$ which is also higher than the GM measured in our study (Covaci et al, 2015)

The urinary BPA values were stratified into quartiles ( $<1.3 \mathrm{ng} / \mathrm{mL}, 1.3-<2.6 \mathrm{ng} / \mathrm{mL}, 2.6-4.9 \mathrm{ng} / \mathrm{mL},>4.9 \mathrm{ng} / \mathrm{mL})$ as shown in table 3 . This allowed us to categorize 4 levels of exposure as follows low, middle, high and extremely high. The highest frequency of distribution was detected in the first quartile and the lowest frequency was in the $4^{\text {th }}$ quartile representing (129) $77.2 \%$ and (5) $3 \%$ respectively of our study group. This denotes the high prevalence of the low BPA exposure among our candidates.

To find out the distribution of the four BPA quartiles within the three social classes in our study group, we did a cross tabulation. The Chi square test showed that high social class children had BPA levels significantly higher than middle and low social class children, $\mathrm{p}=0.014$, as illustrated in table 5 .

In addition, Urinary BPA and BPA/Creatinine levels were log-transformed to improve normality of the distribution. ANOVA and post-Hoc tests were done to compare urinary BPA concentration in different social class groups. Log total BPA, BPA /Creatinine gm and log BPA /creatinine gm showed significant statistical differences between the three groups being highest in the high social class group (table 4). In contrast to our finding, the Australian study done by AL Heffernan et al, found no relation between the socioeconomic status and the total urinary BPA levels (AL Heffernan et al, 2014). In the NHANES, Nelson et al did a totally opposite conclusion to ours; they deduced that a higher BPA exposure was encountered in lower socioeconomic class that was mainly determined by the family income (Nelson et al, 2012). This may be explained by different dietary behaviors between developed and developing countries. High social class population in developing nations as Egypt tend to high consumption of canned food, bottled water and overuse of microwave. The same behaviors are adopted by low social classes in developed countries and are hypothesized to increase BPA exposure. Thus rendering the comparison unfeasible between different studies.

\section{CONCLUSION}

Urinary BPA concentrations exhibited low values in more than three fourths of the studied children and adolescents indicating low exposure. The highest levels were detected in children from high socioeconomic standard. Excessive use of plastic bottles, microwave plastic wares and consumption of canned food may be the sources of increased exposure in this group. Directing attention and increasing awareness of vulnerable groups may help to protect growing children from future chronic adult diseases

\section{ACKNOWLEDGEMENTS}

The authors thank all the candidates who participated in the study and their parents.

\section{Financial support and sponsorship: Nil.}

Conflict of Interests: There are no conflicts of interest.

\section{REFERENCES}

Abdel-Aziz H. Egypt: An overview of the food market. Service USC. Alexandria, Egypt: U.S Commercial Service in Alexandria, Egypt; 2008. p. 3.

AL Heffernan, Sly PD, Toms LML et al. Bisphenol A exposure is not associated with area-level socioeconomic index in Australian children using pooled urine samples; Environ Sci Pollut Res 2014; 21:9344-9355.

Barr D, Wilder L, Caudill S et al. Urinary creatinine concentrations in the U.S. Population: implications for urinary biologic monitoring measurements," Environmental Health Perspectives 2005; 113: 192-200.

Becker K, Goeen T, Seiwert M et al. Ger ES IV: phthalate metabolites and bisphenol $\mathrm{A}$ in urine of German children. Int $\mathrm{J}$ Hyg Environ Health 2009; 212:685-692. doi:10.1016/j.ijheh.2009.08.002

Bushnik T, Haines D, Levallois P et al, Lead and bisphenol A in the Canadian population, catalogue no. 82-003-XPE. Health Rep 2010; 21:1-13.

Covaci A, Den Hond E, Geens $\mathrm{T}$ et al. Urinary BPA measurements in children and mothers from six European member states: Overall results and determinants of exposure Environmental Research 2015; 141: 77-85.

Food and Drug Administration. Update on Bisphenol A for Use in Food Contact Applications U.S. January 2010. [ONLINE] Available online

at

https://www.fda.gov/downloads/NewsEvents/PublicHealthFocus/UCM197 778.pdf (Accessed 27 September 2017)

Galal OM. The nutrition transition in Egypt: obesity, under nutrition and the food consumption context. Public Health Nutr 2002; 5:141-148. doi:10.1186/1476-069X-11-20

Gutman I, Bergmeyer HU. Methods of Enzymatic analysis. 2nd ed., Urea 1974; 1791.

Henry RJ. Clinical chemistry, Principles and techniques, 2nd ed., Harper and Row 1974; P. 525.

Inadera H. Neurological Effects of Bisphenol $A$ and its Analogues. Int. J. Med. Sci. 2015; 12(12): 926-936.

Koch HM and Calafat AM. Review: human body burdens of chemicals used in plastic manufacture. Phil Trans R Soc B 2009; 364: 2063-2078. doi:10.1098/rstb.2008.0208

Matsumoto A, Kunugita N, Kitagawa K et al. Bisphenol A levels in human urine, Environ Health Perspect 2003; vol. 111: 101-104.

Nahar MS, Soliman AS, Colacino JA et al. Urinary bisphenol A concentrations in girls from rural and urban Egypt: a pilot study Environmental Health 2012; 11:20

Nelson JW, Scammell MK, Hatch EE et al. Social disparities in exposures to bisphenol A and polyfluoroalkyl chemicals: a cross-sectional study within NHANES 2003-2006. Environ Health 2012; 11:10. doi:10.1186/1476-069x-11-10 http://www.ehjournal.net/content/11/1/10

Newbold RR, Padilla-Banks E and Jefferson WN. Environmental estrogens and obesity. Molecular and Cellular Endocrinology. 2009; 304(1-2):84-89. [PMC free article] [PubMed] 
Park JE, Park K. Textbook of preventive social medicine, 7th edition, Messers Banarsidas, Bhanot Publisher, 1268, Napier Town. 1979:81.

Rubin BS and Soto AM. Bisphenol A: perinatal exposure and body weight. Molecular and Cellular Endocrinology. 2009; 304 (1-2):5562. [PMC free article] [PubMed]

Scheuplein R, Charnley G and Doursen M. Differential sensitivity of children and adults to chemical toxicity: I. Biological basis. Regul Toxicol Pharmacol 2002; 35:429-447. doi:10.1006/rtph.2002.1558

Shankar A and Teppala S. Relationship between urinary bisphenol A levels and diabetes mellitus. Journal of Clinical Endocrinology and Metabolism. 2011; 96(12):3822-3826. [PMC free article] [PubMed]

Trasande, L, Vandenberg LN and Bourguignon JP et al. Peerreviewed and unbiased research, rather than "sound science", should be used to evaluate endocrine-disrupting chemicals. Journal of Epidemiology and Community Health 2016; 70(11), 1051-1056. http://doi.org/10.1136/jech-2016-207841

Vandenberg LN, Hauser R, Marcus M et al. Human exposure to bisphenol A (BPA). Reprod Toxicol 2007; 24:139- 177. doi:10.1016/j.reprotox.2007.07.010

Von Goetz N, Wormuth M, Scheringer M et al. Bisphenol A: how the most relevant exposure sources contribute to total consumer exposure. Risk Anal 2010; 30:473-487. doi:10.1111/j.15396924.2009.01345.x

World Health Organisation. Children's health and the environment. A global persepctive. World Health Organisation, Geneva 2004.

World Health Organisation. Summary of principles for evaluating health risks in children associated with exposure to chemicals. Children's Environmental Health. World Health Organization, Geneva 2011.

\section{How to cite this article:}

Gabr AA, Mahfouz NN, Shady MMA, Youssef MM, El-Din EMS, Kamhawy AH, Hussein J, Ibrahim TS, Abbas MA. Socioeconomic position as a risk factor for BPA exposure in a sample of Egyptian children. J App Pharm Sci, 2017; 7 (12): 084089. 